Epidemiology and Infection

cambridge.org/hyg

\section{From the Field}

Cite this article: Perez Duque M, San-Bento A, Léon L, Custódio $P$, Esperança MA,

Albuquerque MJ, Nascimento M, Balasegaram S, Sá Machado R (2021). Mumps outbreak among fully vaccinated school-age children and young adults, Portugal 2019/2020.

Epidemiology and Infection 149, e205, 1-3.

https://doi.org/10.1017/S0950268821002028

Received: 19 August 2021

Accepted: 24 August 2021

\section{Key words:}

MMR vaccination; Mumps; Outbreaks; Vaccine preventable diseases; Virology

Author for correspondence:

Mariana Perez Duque,

E-mail: marianapduque@dgs.min-saude.pt

\section{Mumps outbreak among fully vaccinated school-age children and young adults, Portugal 2019/2020}

\author{
Mariana Perez Duque ${ }^{1,2}$ (D), Ana San-Bento ${ }^{1,3}$, Lourdes Léon33, Paula Custódio3, \\ Maria Anjos Esperança ${ }^{3}$, Maria João Albuquerque ${ }^{1}$, Marina Nascimento ${ }^{1}$, \\ Sooria Balasegaram ${ }^{2,4}$ and Rita Sá Machado1,2
}

${ }^{1}$ Directorate-General of Health, Lisbon, Portugal; ${ }^{2}$ European Program for Intervention Epidemiology Training (EPIET), European Centre for Disease Prevention and Control (ECDC), Stockholm, Sweden; ${ }^{3}$ Public Health Unit, ACES Médio Tejo, Torres Novas, Portugal and ${ }^{4}$ Public Health England, London, UK

\begin{abstract}
On 16-17 January 2020, four suspected mumps cases were reported to the local Public Health Authorities with an epidemiological link to a local school and football club. Of 18 suspected cases identified, 14 were included in this study. Laboratory results confirmed mumps virus as the cause and further sequencing identified genotype G. Our findings highlight that even with a high MMR vaccine coverage, mumps outbreaks in children and young adults can occur. Since most of the cases had documented immunity for mumps, we hypothesise that waning immunity or discordant mumps virus strains are likely explanations for this outbreak.
\end{abstract}

\section{Manuscript}

On 16-17 January 2020, four cases of suspected mumps were reported to the National Epidemiological Surveillance System (SINAVE). The four suspect cases were males aged 4 -14 years and attended the same local football club. A case definition and classification for this cluster were adapted from the European Union Commission Implementing Decision 2018/945 [1]. We defined cases as those that occurred between 1 December and 29 February with an epidemiological link to the local school or the football club or to a confirmed case. A confirmed case was defined as having one of the following laboratory confirmed results for mumps virus: mumps virus isolation in a biological sample; detection of mumps virus nucleic acid; or mumps virus specific antibody response characteristic of acute infection (IgM) in serum or saliva, with or without the clinical criteria i.e. self- or doctor-reported acute onset of salivary gland swelling (more often parotitis) with or without fever. A probable case was defined as an individual having the clinical and epidemiological criteria. A possible case was an individual who reported only the clinical features.

Mumps is a notifiable disease in Portugal and is reported via SINAVE by clinicians and microbiological laboratories [2]. Since 2014, mumps cases can be electronically reported by a clinician or, after 2017, by a laboratory professional, when a case is suspected or confirmed. This notification leads to an epidemiological investigation by the local public health team to implement prevention and control measures (contact tracing, case isolation and immunisation of susceptibles) [3].

After the first alert, cases were retrospectively identified in SINAVE by telephone interviews and field visits. We visited both the school to meet teachers and coordinators and the football club facilities. During the visit to the secondary school, the presence of temporary facilities for a primary school were identified in the backyard of the first. Due to construction works, primary school classes were being temporarily taught in container facilities. The football club director and coach were contacted by telephone to provide information on other possible cases. The teachers and coach noted that some students missed days of school and workouts due to sick leave. Therefore, it was decided to investigate the said absences further to identify potential undiagnosed cases in the previous month

Onset of symptoms of the first case was on 14 December 2019, during the Christmas break for schoolchildren, and of the second known case on 23 December, nine days later. The last case's onset was 50 days after the first, on 2 February 2020 (Fig. 1).

All mumps suspected cases notified to the local Public Health team since December 2019 were investigated for a possible link to this outbreak, in addition to the ones actively identified during the field visit. A total of 18 cases were assessed and samples for microbiological testing were collected from five cases. Four cases were found not be related to this outbreak. Of the four, two cases had no epidemiological link to this outbreak (sporadic cases). The other two cases had an epidemiological link but had non-confirmatory clinical symptoms and 


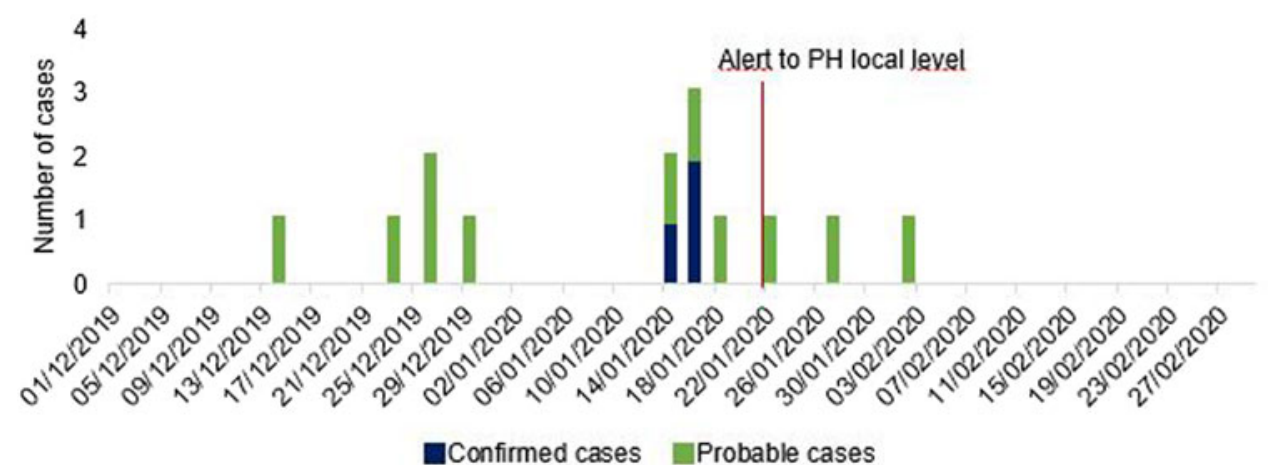

Fig. 1. Epidemic curve of mumps confirmed and probable cases, by date of onset of symptoms, Portugal, December-February 2020, $(n=14)$.

Table 1. Characteristics of mumps confirmed and probable cases, Portugal, December-February 2020, $(n=14)$

\begin{tabular}{lrr}
\hline & Confirmed cases $(n=3)^{\mathrm{a}}$ & Probable cases $(n=11)^{\mathrm{a}}$ \\
\hline Age ${ }^{\mathrm{b}}$ & $15.3 \pm 11.0$ & $25.9 \pm 15.6$ \\
\hline Male & $3(100)$ & $9(81.8)$ \\
\hline Fever & $3(100)$ & $4(36.4)$ \\
\hline MMR vaccination & & $1(9.1)$ \\
\hline One dose & $3(0)$ & $8(72.7)$ \\
\hline Two doses & $0(0)$ & $1(9.1)$ \\
\hline Unknown & $0(0)$ & $1(9.1)$ \\
\hline Not vaccinated & $7.0(3.0)$ & 1.0 \\
\hline Age at the time of last MMR dose & $8.8(8.4)$ & $13.5(9.0)$ \\
\hline Time (years) between last MMR dose and onset of symptoms & & \\
\hline
\end{tabular}

MMR, mumps-measles-rubella vaccine; s.D., standard deviation.

${ }^{\text {a }}$ Statistics presented: mean (S.D.); no. (\%).

${ }^{\mathrm{b}}$ At the time of the study.

signs. Therefore, 14 notified cases met criteria to be included in our case definition, three as confirmed cases and 11 as probable cases.

The three confirmed cases were ascertained by mumps virus nucleic acid detected through polymerase-chain reaction test (PCR) and one had simultaneously an inconclusive IgM test result. The other two cases tested had a negative result both for mumps virus IgM and nucleic acid detection by PCR. From confirmed cases, virus sequencing was able to identify genotype G. Two probable cases had tested negative for both mumps virus IgM and nucleic acid detection by PCR but these findings were deemed unreliable by the outbreak investigation team and National Laboratory Focal Point since sample collection and testing was too long after onset of symptoms, which makes viral detection unlikely. Henceforth, these two cases were retained as probable cases.

Regarding age and sex, $86 \%$ of cases $(n=12)$ were male, including all confirmed cases, and ages ranged from 7 to 59 years old (Table 1). We had information on vaccination status for 13 cases; all were fully vaccinated with two doses of MMR according to national schedule except for one, who had had one dose only of MMR vaccine. The 14th (probable) case was not vaccinated with MMR vaccine due to medical history of past measles infection, and so, never received this vaccine. Available information on vaccines administered showed that all of them were Jeryl Lynn strain derived, thus conferring genotype A protection.

All cases had self- or doctor-reported acute onset of parotitis, but only half, including all confirmed cases, had history of fever. The mean time between symptom onset and diagnosis was 1 day, except for one case who did not seek healthcare and was retrospectively found and diagnosed by the local Public Health team 42 days later.

Outbreak-control measures were instituted at the school and the football club immediately after the Public Health unit was notified on 16 January 2020. The vaccination status of children in the affected schools, both primary and secondary, was reviewed. Since MMR vaccine is included in the National Immunization Program, children without a complete scheme were called to be vaccinated. Cases were excluded from school for at least five days after the appearance of parotitis [4]. During our investigation, no other mumps cases and clusters were detected in this region. Concerning public health measures to prevent and control outbreaks, as well as more broadly health policies, third dose mumps vaccine is being applied in the United States of America and other European countries to prevent spread of mumps outbreaks to at-risk but non-exposed people, and also 
to limit further complications $[5,6]$. There is no strong evidence to endorse a third dose of mumps vaccine in small outbreaks, and is not recommended in Portugal.

A possible drawback of our investigation was the inability to conduct an analytical study that was planned because of resources being allocated to the coronavirus disease 2019 (COVID-19) epidemic which had just started. The main objective of this further analysis was to conduct a case-control study to determine clinical and laboratorial risk factors related to the surge of mumps in vaccinated individuals compared to controls within the same age group. In this study, we would like to question if symptomatic mumps in vaccinated individuals was associated with a non-effective immune response. In addition, there might have been under-ascertainment of cases since most mumps cases have mild-to-moderate symptoms. Moreover, lack of clinical awareness of mumps in vaccinated individuals can underestimate its true incidence. Although public health teams can report disease complications in SINAVE when epidemiological investigations are still ongoing, some of them may have occurred later. We did not routinely ask for follow-up data on cases reported to SINAVE. Moreover, the poor sensitivity of parotitis IgM tests in vaccinated patients may also have contributed to an underestimation of cases, as well as late specimen collection and analysis (28).

We hypothesised that waning immunity or discordant mumps virus strains (circulating and vaccine) are likely explanations for this outbreak to have occurred. Mumps neutralising antibodies are partly strain-specific, cross-immunity from neutralisation titres in vaccinated individuals are significantly lower for strains that are not included in the vaccine administered $[7,8]$. In the last national serological survey, prevalence of mumps antibodies was $90.3 \%$, higher than in the previous one in 2001-2002 $(81.4 \%)$. However, there was an increase in the number of susceptible individuals between 15 and 19 years [9]. Even though Portugal has one of the highest MMR vaccine coverages of Europe, exceeding $96 \%$ for two doses of this vaccine [10], in recent years several outbreaks of mumps have occurred worldwide, including in Portugal, and mostly in vaccinated teenagers and young adults $[5,11-14]$. Laboratory studies on cases, as well as analysis of antibody and neutralisation assays, could give us more answers on immune status and its response [15].

Our investigation supports existing evidence that genotype $G$ mumps outbreaks in children and young adults vaccinated with Jeryl Lynn (genotype A strains) have been not uncommon in the last decades, even in countries with high vaccine coverage [8]. These outbreaks are associated with mild and moderate clinical symptoms that do not always lead to seek healthcare services for medical advice. The outbreak size then depends on both herd immunity and the settings where cases occur, especially in crowded situations. We recommend that mumps should be excluded in symptomatic salivary gland infections in school-age children and young adults, and clinical suspicion should be raised by general practitioners and other physicians regardless of immunisation state. We also would like to endorse future research studies on similar outbreaks in vaccinated people.

Acknowledgements. We would like to acknowledge the National Reference Laboratory (INSA) for vaccine-preventable diseases for the laboratorial analysis work. We also would like to thank the football club and local school for availability and close collaboration in this investigation.

Author's contributions. Conceptualisation: Mariana Perez Duque, Ana San-Bento, Rita Sá Machado. Methodology: Mariana Perez Duque, Ana San-Bento, Maria João Albuquerque, Marina Nascimento, Sooria,
Balasegaram, Rita Sá Machado. Formal analysis and investigation: Mariana Perez Duque, Ana San-Bento, Lourdes Léon, Paula Custódio, Maria dos Anjos Esperança, Rita Sá Machado. Writing - original draft preparation: Mariana Perez Duque; Writing - review and editing: Mariana Perez Duque, Ana San-Bento, Lourdes Léon, Paula Custódio, Maria dos Anjos Esperança, Maria João Albuquerque, Marina Nascimento, Sooria Balasegaram, Rita Sá Machado. Supervision: Sooria Balasegaram, Rita Sá Machado.

Financial support. The authors did not receive support from any organisation for the submitted work.

Ethical standards. Written informed consent was waived as this study was carried out for emerging infectious disease purposes and is part of a continuing public health outbreak investigation, under national authorisation of the Directorate-General of Health, entering in the epidemiological surveillance component.

Conflicts of interest. None of the authors has conflict of interests to declare. The contents of this article are solely the responsibility of the authors and do not necessarily represent the views of the affiliated institutions.

Data availability statement. The data that sustain the findings of this study are available from the Portuguese Directorate-General of Health (DGS). Restrictions apply to the availability of these data, which were used under licence for this study. Data are available from the authors with the permission of DGS.

\section{References}

1. Commission E (2018) Executive decision 2018/945. European Union Official Journal 170, 1-74.

2. Portuguese Directorate-General of Health (2019) Despacho n.o 12513-B/2019. Available at https://dre.pt/home/-/dre/127659250/details.

3. Portuguese Directorate-General of Health (2015) Sistema Nacional de Vigilância Epidemiológica (SINAVE) Orientação para Autoridade de Saúde. Available at https:/www.dgs.pt/ficheiros-de-upload-2013/sinaveorientacao-as-e-usp-pdf.aspx.

4. Mumps BA (2016) Control of Communicable Diseases Manual. Available at https://ccdm.aphapublications.org/doi/abs/10.2105/CCDM.2745.103.

5. Veneti L et al. (2018) Large outbreak of mumps virus genotype g among vaccinated students in Norway, 2015 to 2016. Eurosurveillance 23, 1-9.

6. Albertson JP et al. (2016) Mumps outbreak at a university and recommendation for a third dose of measles-mumps-rubella vaccine - Illinois, 2015-2016. Morbidity and Mortality Weekly Report 65, 2015-2016.

7. Hamborsky J, Kroger A and Wolfe SE (2015) Epidemiology and Prevention of Vaccine-Preventable Diseases. Centers for Disease Control and Prevention. 512. Available at: https://www.cdc.gov/vaccines/pubs/ pinkbook/downloads/table-of-contents.pdf.

8. Gouma S et al. (2018) Differences in antigenic sites and other functional regions between genotype $A$ and $G$ mumps virus surface proteins. Scientific Reports 8, 1-10.

9. Instituto Nacional de Saúde Doutor Ricardo Jorge (2017) Inquérito Serológico Nacional 2015-2016: Doenças Evitáveis por Vacinação. INSA IP, editor. Lisboa.

10. Portuguese Directorate-General of Health (2020) Boletim do Programa Nacional de Vacinação.

11. Dias JA et al. (1996) Mumps epidemic in Portugal despite high vaccine coverage - preliminary report. Eurosurveillance 1, 160.

12. Palminha P, Vinagre E and Cordeiro E (2013) Parotidite epidémica em adolescentes vacinados entre 2012-2013. Observações - Boletim Epidemiológico. Número Especial. INSA 46, 2013.

13. Vygen S et al. (2016) Waning immunity against mumps in vaccinated young adults, France 2013. Eurosurveillance 21, 1-8.

14. Ströhle A et al. (1997) Mumps epidemic in vaccinated children in west Switzerland. Schweizerische Medizinische Wochenschrift 127, 1124-1133.

15. Vaidya SR et al. (2018) Utility of neutralization test for laboratory diagnosis of suspected mumps. Microbiology and Immunology 62, 243-247. 